\title{
Challenges of Iran Health Transformation Plan about Inpatients Payment: Viewpoint of Experts
}

\author{
Masoud Ferdosi, ${ }^{1}$ Shohreh Kabiri, ${ }^{2, *}$ Mahmoud Keyvanara, ${ }^{3}$ and Mohammad Hosein \\ Yarmohammadian ${ }^{4}$ \\ ${ }^{1}$ Associate Professor, Health Management and Economics Research center (HMERC), Isfahan University of Medical Sciences, Isfahan, IR Iran \\ ${ }^{2}$ MSc Student of Health Service Management, Isfahan University of Medical Sciences, Isfahan, IR Iran \\ ${ }^{3}$ Associate Professor, Health Management and Economics Research center (HMERC), Isfahan University of Medical Sciences, Isfahan, IR Iran \\ ${ }^{4}$ Full Professor, Health Management and Economics Research center (HMERC), Isfahan University of Medical Sciences, Isfahan, IR Iran \\ "Corresponding author: Shohreh Kabiri, Isfahan University of Medical Sciences, Azadi square, Hezaejerib Street, Isfahan, IR Iran. Tel: +98-9137976067, E-mail: \\ sh.kabiri70@yahoo.com
}

Received 2016 September 06; Revised 2016 November 19; Accepted 2016 December 04.

\begin{abstract}
Background: The health transformation plan (HTP) was put into action in Iran, in 2014, with 8 service packages. This plan was not implemented as a pilot and therefore, various problems and barriers have since emerged.

Objectives: The aim of this study was to identify the economic challenges of inpatient payment reduction directive in HTP from the perspectives of 2 groups of experts in levels of hospital and university held in 2 time periods.

Methods: In this qualitative study, data were collected through semi-structured interviews with 20 participants involved in the healthcare reform in hospitals as well as the executive committee of HTP in universities.

Results: Data collection resulted in 36 descriptive codes presenting the economic challenges of the payment reduction directive in thems of insurance / tariffs and financial affairs in the period of 3 months and 1 year since the beginning. Interviewees then suggested their solutions.

Conclusions: Challenges trends over times show that some parts of challenges are changing. In addition, challenges interact with each other and could be avoided just by appropriate planning. On the other hand, execution of this directive was extremely costly for the government; it would be better to allocate resources with meticulous planning and designs.
\end{abstract}

Keywords: Health Transformation Plan, Economic Challenges, Solutions, Iran

\section{Background}

One of the greatest challenges facing health system policy makers is how to finance health services, which has been addressed recently (2014) in HTP (1). The government has tried to give poor people an opportunity to use inexpensive health services. This plan consists of 8 practical packages one of the most important is decreasing the rate of costs in medical hospitals. The implementation of the health sector evolution leads to justice in accessing healthcare services (2).

In this plan, all Iranians have basic insurance coverage. Villagers and cities with a population under 20,000, as well as other people who refer to the hospital by the reference system, are under this reference plan as well; they only pay $5 \%$ of the cost of the service. Private hospitals in the cities that lack public hospitals are also included in this plan and insurance companies of Iran have to cover all the people who are referred to these hospitals (3).

The plan is mainly supported through the following financial sources: increased public annual budget of health sector (around 59\% increase in 2015 compared to the 2014), resources of the targeted subsidies' law (10\% of total subsidies) and a specific $1 \%$ value added tax (VAT) for health. The financial sources are estimated to be 70\% higher in 2015 (March 21, 2015 - March 20, 2016) compared to 2014 (March 21, 2014 - March 20, 2015) (4).

This paper examines the economic challenges and solutions of inpatient payment reduction, directive of Iran's HTP established in 2014, in public hospitals from the viewpoints of those involved in the HTP in Isfahan Province.

\section{Objectives}

The aim of this study was to identify the economic challenges of inpatient payment reduction directive in HTP from the perspectives of experts including hospital staff as well as authorities in the executive committee for HTP in the university level. These challenges were identified in 2 time periods ( 3 months and 1 year after the initiation of the plan). Some solutions were also presented by participants. 


\section{Methods}

In this qualitative research, participants were selected through purposive sampling. Some of the participants were engaged with this package in covered hospitals while others were from authorities in the executive committee for HTP in Isfahan university of Medical Sciences (IUMS). The inclusion criteria of participations were:

- Staff in different wards of covered hospitals who are involved in the plan especially in the inpatient payment reduction directive

- Chief executives of the HTP at university level are closely involved in the plan

- Being accessible for the researcher

- Their willingness to participate in interviews

In addition, participants were promised that a copy of the results would be presented to them. Therefore, they were more motivated to participate.

The interview began with 16 participants and data were saturated after 20 interviews. The study instrument was a semi-structured questionnaire as an interview guide. There were 9 questions in this questionnaire and the number as well as type of questions varied according to interviews, conditions, and study goals. Questions included a status change after the plan to range challenges in various themes (it is noteworthy that identified challenges were in several themes, however, in this paper, the theme of economic challenges are presented). First, researchers conducted a pilot interview to increase their skills, reliability, as well as validity of interview. Interviewees were satisfied, however, if there was not enough time they were referred to relevant experts. To maintain confidentiality, participants were completely anonymous and the names of individuals as well as hospitals were not expressed.

Interviews were held in 2 phases. In the first phase (3 months after the plan initiation) 7 interviews were held while in the second phase (1 year after it) there was 13 interviews.. Each interview lasted for 30 to 40 minutes. Participants' voices were recorded with their consent and were transcribed shortly after their interview.

The method of data analysis was thematic analyze, which was performed manually, without any software. First, a detailed analysis of the data resulted in basic or descriptive themes then, axial or interpretive codes were extracted from basic themes, and finally, explanatory codes (36) were extracted from axial codes.

To insure data reliability and validity, interviewers conducted a pilot interview to enhance their skills. In addition, the researcher constantly assessed the transcribed interviews as well as the codes with the participants. Finally, data were returned to the participants to ensure their validity. At the end, challenges of HTP implementation as well as sustainability were extracted and some solutions were suggested.

\section{Results}

Challenge-related issues are classified into 2 subthemes of insurance/tariffs and financial affairs, which are presented in Tables 1 and 2. Challenges in terms of time were divided in a 3-month and a 1-year period in 2 columns.

\subsection{Suggested Solutions by Participants}

1. To develop the plan budget, meticulous planning is needed considering each hospital circumstances and the situation of each hospital should be taken into account.

2. The plan budget should be paid on time to prevent hospital debts.

3. Insurance organizations should control the budget in order to prevent hospitals from unnecessary and inappropriate spending. It also causes optimal use of funds. Therefore, hospitals and universities are not involved together.

4. It would have been better if the pay for performance plan had started a while after HTP and a renewal of hospital resources to avoid personnel dissatisfaction.

5. Financial resources of the plan had to be allocated to infrastructures first and the plan had to be initiated after providing hospitals with sufficient infrastructure equipment as well as facilities.

6. Hospital managers should spend the resources more properly to avoid budget deficit.

\section{Discussion}

This study revealed the challenges of the payment reduction directive for hospitalized patients in public hospitals from an economic perspective.

Some of the challenges in the first 3 months are not mentioned in the 1-year period interview indicating that they might be resolved. The most important of them is coordination of insurance companies, due to the fact that in the first few months, some insurance companies decreased their obligations as reported by the participants.

On the other hand, in the 1-year period interview, some new challenges were added. Insurance companies experienced higher expenditures, as their obligations extended with initiation of the plan. Increased tariffs related to the third phase of the plan, however, created new challenges for insurers, which play important roles in this directive. They believe that because new tariffs are higher than before, they should pay more, without any reliable financial 
Table 1. Specifications of Participants

\begin{tabular}{|c|c|c|c|c|}
\hline Position & Organisation & Educational Degree & Sex & Time Period \\
\hline Head of Committee of Medicines and Medical Equipment & Isfahan University of Medical Science & Ph.D. & Male & \multirow{7}{*}{ Three months after HTP } \\
\hline Actuary of the Executive Committee & Isfahan University of Medical Science & Ph.D. & Male & \\
\hline Executive Team Manager of Directive No. 8 & Isfahan University of Medical Science & Ph.D. & Female & \\
\hline Central Secretariat Manager of the Executive Committee & Isfahan University of Medical Science & Bachelor & Male & \\
\hline Insurance and Resources Committee Manager & Isfahan University of Medical Science & General practitioner & Male & \\
\hline Productivity Manager & Isfahan University of Medical Science & General practitioner & Male & \\
\hline Hospital Management & University Hospital & General practitioner & Male & \\
\hline Insurance Officer & University Hospital & Bachelor & Male & \multirow{13}{*}{ One-year after HTP } \\
\hline Human Resources Manager & University Hospital & MA & Female & \\
\hline Fund manager & University Hospital & Bachelor & Female & \\
\hline Hospital Information System Manager & University Hospital & Bachelor & Male & \\
\hline Pharmacy Manager & University Hospital & Ph.D. & Male & \\
\hline Financial Manager & University Hospital & Bachelor & Male & \\
\hline Clinical Supervisors & University Hospital & Bachelor & Female & \\
\hline Hospital Manager & University Hospital & General practitioner & Male & \\
\hline Financial Manager & University Hospital & Bachelor & Male & \\
\hline Insurance Officer & University Hospital & Bachelor & Female & \\
\hline Pharmacy Manager & University Hospital & Ph.D. & Male & \\
\hline Central Secretariat Manager of the Executive Committee & Isfahan University of Medical Science & Bachelor & Male & \\
\hline Executive Team Manager of Reduced Payment Reduction Directive & Isfahan University of Medical Science & MA & Male & \\
\hline
\end{tabular}

resources. Furthermore some outpatients who cannot afford the costs might be hospitalized instead and therefore the rate of hospitalization increased.

The most important complaint of hospitals in this time was delay in subsidy payment. Delay in personnel payments is another financial challenge associated with late subsidy payment. One of committee officials believes that the challenge of budget deficit has resulted from additional obligations, including expensive drugs and equipment.

There are also some questions, which have remained unchanged. The most important of them was how long the budget for the plan is going to be paid? Increasing delay on budget payment has escalated this concern. Governments' expenses are increasing and according to the interviewees, this plan, while focusing on patients, has incurred numerous costs with few cost control mechanisms. Hospitals suffered from worn-out equipment and facilities. Surge of patients referring to hospitals for therapy exacerbated this problem. Thus, improving infrastructures is of greater importance.

Maziar Moradi-Lakeh et al. in their research titled "Health Sector Evolution Plan in Iran; equity and sustainability concerns" concluded that securing financial sources and fairness of the financial contribution to the new programs are the main concerns of policy-makers. Healthcare providers' concerns (as powerful and influential stakeholders) potentially threat the sustainability and efficiency of the plan. Previous experiences on extending health insurance coverage show that they can lead to a regressive healthcare financing and threat financial equity. To secure financial sources and to increase fairness, the contributions of people to new interventions should be progressive by their income as well as wealth to increase sustainability of the reform programs (4). Researcher's focus on results of "continuing of financial plan", "limited financial resources and allocations", and "volatile financing and following the goals along with permanent injection of financial resources", which are consistent with the findings of the study above.

Kiaei et al. examined the viewpoint of hospital managers regarding the recent health care reform in teaching hospitals. As they said, more than half of the administration staff stated that this plan was not successful in the decreasing payment rate (3), which is not consistent with this study, due to the fact that our study period is wider than theirs.

Viroj Tangcharoensathien investigated the challenges facing realization of public health insurance within implemented reforms in Southeast Asia. Results indicated that Laos and Cambodia were the 2 countries with limited and poor resources, which relied on health equity funds to service the poor and faced 2 major challenges of reliable investment as well as identification of qualified poor people in expanding public health insurance (5). In the present study, high dependency of health insurance sys- 
Table 2. Codes Extracted in the Economic Dimension of Inpatient Payment Reduction Directive of HTP in Covered Public Hospitals

\begin{tabular}{|c|c|c|c|c|}
\hline Themes & Sub-Themes & $\begin{array}{l}\text { Challenges Specific to one Year after } \\
\text { HTP }\end{array}$ & $\begin{array}{l}\text { Challenges Specific to Three Months } \\
\text { after HTP }\end{array}$ & $\begin{array}{l}\text { Challenges Common to Both } \\
\text { Three-Month and One-Year Periods }\end{array}$ \\
\hline \multirow{20}{*}{ Economic Challenges } & \multirow{13}{*}{ Financial affairs } & $\begin{array}{l}\text { 1. Mistakes in directing financial sources } \\
\text { to healthcare and overlooking } \\
\text { infrastructures }\end{array}$ & $\begin{array}{l}\text { 1. First budget allocated on the basis of } \\
\text { hospitals' authorized beds }{ }^{\mathrm{a}}\end{array}$ & $\begin{array}{l}\text { 1. Concerns about continuation of the } \\
\text { plan budget }\end{array}$ \\
\hline & & 2. Delay payment of health subsidies ${ }^{\mathrm{b}}$ & 2. Absolute focus of the plan on expenses & 2. Increased government expenses \\
\hline & & $\begin{array}{l}\text { 3. Spending the budget for unnecessary } \\
\text { purposes not defined by the plan }{ }^{c}\end{array}$ & & $\begin{array}{l}\text { 3. Hospital budget deficit and fast } \\
\text { spending of the budget }\end{array}$ \\
\hline & & 4. Delay in personnel payment & & $\begin{array}{l}\text { 4. Continuation of the goals along with } \\
\text { continuous injection of financial } \\
\text { resources }\end{array}$ \\
\hline & & $\begin{array}{l}\text { 5. Lower subsidies compared to the } \\
\text { requested list }\end{array}$ & & $\begin{array}{l}\text { 5. Increased costs of purchasing } \\
\text { operating room equipment, prosthesis, } \\
\text { drug and laboratory tests }\end{array}$ \\
\hline & & $\begin{array}{l}\text { 6. Using hospitals' exclusive incomes } \\
\text { instead of the plan budget }\end{array}$ & & 6. High debts of hospitals ${ }^{\mathrm{d}}$ \\
\hline & & 7. Negative balance sheet of hospital ${ }^{\mathrm{e}}$ & & \\
\hline & & $\begin{array}{l}\text { 8. Limited financial resources and } \\
\text { allocations }\end{array}$ & & $\begin{array}{l}\text { 7. Inappropriate resource management in } \\
\text { hospitals }\end{array}$ \\
\hline & & $\begin{array}{l}\text { 9. Impacts on financing other industrial } \\
\text { sectors due to increased financial needs } \\
\text { for continuation of tariff equalization } \\
\text { policies }\end{array}$ & & \\
\hline & & $\begin{array}{l}\text { 10. Additional obligations of hospitals } \\
\text { compared to previous years }\end{array}$ & & \\
\hline & & $\begin{array}{l}\text { 11. Introducing new systems into financial } \\
\text { domains and problem with data entry } \\
\text { processes }\end{array}$ & & \\
\hline & & $\begin{array}{l}\text { 12. Unstable financial resources for } \\
\text { hospital purchases }\end{array}$ & & \\
\hline & & $\begin{array}{l}\text { 13. Bias in directing the resources of the } \\
\text { directive } \mathrm{f}^{\mathrm{f}}\end{array}$ & & \\
\hline & \multirow{7}{*}{ Insurance/tariffs } & $\begin{array}{l}\text { 1. Increased insurance organization } \\
\text { expenses }\end{array}$ & 1. Overlapping insurance companies & \\
\hline & & $\begin{array}{l}\text { 2. Discrepancy between patient billing } \\
\text { forms of insurance companies and the } \\
\text { Ministry }\end{array}$ & $\begin{array}{l}\text { 2. Healthcare insurance as a motivation } \\
\text { for people to refer to hospitals for } \\
\text { treatment }\end{array}$ & \\
\hline & & $\begin{array}{l}\text { 4. Delayed payment of } 60 \% \text { obligations to } \\
\text { hospitals by insurance companies }\end{array}$ & $\begin{array}{l}\text { 4. Reduction of some insurance } \\
\text { companies obligations }\end{array}$ & \\
\hline & & 5. Increased insurance deductions $\mathrm{g}$ & $\begin{array}{l}\text { 5. The opposition of private hospitals to } \\
\text { the tariffs for referring patients }\end{array}$ & \\
\hline & & $\begin{array}{l}\text { 6. Replacing insurance officers of } \\
\text { insurance companies and arbitrary } \\
\text { payments to hospitals }\end{array}$ & $\begin{array}{l}\text { 6. People's use of health subsidies instead } \\
\text { of complementary insurance with the } \\
\text { initiation of the plan }\end{array}$ & \\
\hline & & $\begin{array}{l}\text { 7. Lack of any resource to compensate the } \\
\text { difference between previous and new } \\
\text { health tariffs for insurance companies }\end{array}$ & & \\
\hline & & $\begin{array}{l}\text { 8. Ineffective outcome of increasing } \\
\text { insurance obligations }\end{array}$ & & \\
\hline
\end{tabular}

${ }^{\mathrm{a}}$ The reason of the first budget allocated on the basis of hospitals' authorized beds was that the number of authorized beds was more than active beds in some hospitals leading to unfair situations.

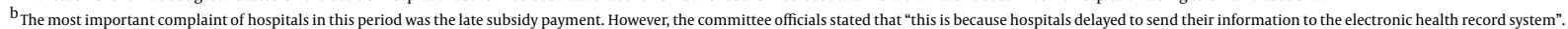
${ }^{c}$ One participant stated that the reason is: "because universities have control over the money, hospitals bill unnecessary expenditures, but the money would be preserved if it was controlled by insurance companies and they would not pay doctors excessively".

d "Hospitals settled most of their debts in the first year of implementation from the plan's budget, while it was not to compensate for these debts. This caused them problems such as budget deficit".

${ }^{e}$ Negative balance sheets is another challenge for hospitals mentioned by one of the interviewees: "payments of insurance and subsidy are not simultaneous, and even the amount paid by the patient in cash goes to the university and there, it is deducted by $10 \%$, hence the balance sheet is negative".

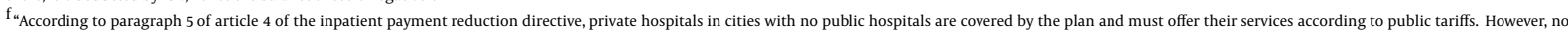
resource has been allocated to this part of the plan".

${ }^{g}$ The reason for this issue may be found in the statement of 1 of the participants: “due to lack of CT scan and MRI in hospitals, these services are offered outside of hospitals and therefore, results are somehow reported with a delay; this causes deductions for patients".

tem on government resources, non-cooperation among insurance companies, and their complaints about ambiguities regarding the resources of compensating tariffs were some of the problems with insurance and consequently realization of public insurance coverage.

Shanlian Hu studied challenges and opportunities of reform in payment methods for healthcare in China. Results indicated that China should develop and establish more powerful measures for expenses and fundamentally rebuild the payment system of providers to be successful. As long as Chinese providers are paid based on FFS (Fee-ForService), increased costs will undermine (6). This research 
also presented irregular increasing costs and dependency of continuing plan to governmental sources as important challenges.

Reshani et al. reviewed the challenges of HTP in a review study. Their results showed that this plan was very costly and has a high dependency on economic conditions; it does not have a road map and was inconsistent with macro policies of our country (7). In the present study the results of "increased government expenditures" and "following the goals along with permanent injection of financial resources" are consistent with the above study.

Khammarnia et al. in their research, review the challenges of HTP from viewpoint of experts in health system. Lack of sustainable resources for this plan was one of the presented challenges that are in accordance with our research.

We have some limitations in this study:

1- Planning and the timing of interviews with participants given the high workload created many restrictions for us.

2- In some cases, the interviewees did not allow audio recording, therefore we had to make notes during interviews

3-A few researches have been done in this area yet, thus, there were some problems when comparing our results with others. We had to use the articles that were financing reform in health sectors.

Finally, the present study found increased costs and continuous dependency of the plan of government resources as important barriers to the continuation of the plan, which require more attention. The pay for the performance plan started a year after the initiation of payment reduction directive and it is said to be closer to justice.

Finally, the present study found increased costs and continuous dependency of the plan of government resources as important barriers to the continuation of the plan. The pay for performance paying mechanism is a new way, which started a year after the initiation of payment reduction directive and it is said to be closer to justice.

\subsection{Conclusions}

The HTP was implemented with a particular focus on financial protection. An important goal of inpatient payment reduction directive is financial protection of people that is so desirable but very costly. Challenges trends over times show that some part of challenges are changing. For example, 3-months after the onset of HTP coordination of insurances was highlighted, while after 1year, insurance payment delay has become important.

Generally, challenges interact with each other and could be avoided just by appropriate planning.
The most important part of the problems probably belong to the challenges, which were constant on both times, as the continuation of the plan budget and increased government expenses. Therefore considering the experts emphasis on continuing the financing plan, the sheer injection of financial resources cannot be a proper solution, due to the fact that it may raise future expectations. Thus, the government should forecast sustainable resources to reduce future challenges.

HTP, like other plans, has both advantages and challenges. Although after implementation, the outcomes of plans would be more apparent, it would rather avoid future challenges by mitigating preparations at the time of planning. Using opinions of individuals involved in the plan at different levels (from university to hospitals) can helps overcome the challenges and minimize the criticisms.

Implication for health policy makers/practice/research/medical education: The results of this study can help policy makers remove barriers and lead to a better implementation of this plan. The variety of the participants' views will also be important for the officials.

\section{Acknowledgments}

The authors appreciate the authorities and managers who participated in this study.

\section{Footnotes}

Author Contribution: Study concept and design: Shohreh Kabiri, Masoud Ferdosi, Mahmoud Keyvanara, Mohammad Hosein Yarmohammadian; acquisition of data: Shohreh Kabiri; analysis and interpretation of data: Shohreh Kabiri, Masoud Ferdosi, Mahmoud Keyvanara, Mohammad hosein Yarmohammadian; drafting of the manuscript: Shohreh Kabiri, Masoud Ferdosi; critical revision of the manuscript for important intellectual content: Shohreh Kabiri, Masoud Ferdosi, Mahmoud Keyvanara; statistical analysis: Shohreh Kabiri, Masoud Ferdosi, Mahmoud Keyvanara; administrative, technical, and material support: Masoud Ferdosi; study supervision: Masoud Ferdosi.

Funding/Support: This research has not had any financial support and has no financial interests related to the material in the manuscript.

\section{References}

1. Tahmasebipour H. Health reform plan and family physician. J General Intern Med Assoc Iran. 2014;1(2). 
2. Iranian Ministry of Health and Medical Education . Collection guidelines for health system reform plan. Health deputy 2014. Available from: https://darman.umsha.ac.ir/uploads.

3. Kiaei MZ, Moradi R, Hasanpoor E, Mohammadi M, Taheri A, Ahmadzadeh MS. Hospital managers' perception of recent health care reform in teaching hospitals of Qazvin, Iran. Biotechnol Health Sci. 2015;2(4).

4. Moradi-Lakeh M, Vosoogh-Moghaddam A. Health Sector Evolution Plan in Iran; Equity and Sustainability Concerns. Int J Health Policy Manag. 2015;4(10):637-40. doi: 10.15171/ijhpm.2015.160. [PubMed: 26673172].
5. Hu S, Tang S, Liu Y, Zhao Y, Escobar ML, De Ferranti D. Reform of how health care is paid for in China: challenges and opportunities. Lancet. 2008;372(9652):1846-53.

6. Roshani M, Alavi A, Hadian M, Jafari H. Challenges of health transformation plan. In: Movahedi F, Asgari $\mathrm{H}$, Alavi A, editors. International Conferences of sustainable reform in health system. Isfahan.

7. khammarnia M, Sadeghi A, Sotudezadeh F. An overview of the challenges of health transformation plan from the viewpoint of executives and experts in health system. National congress on healthcare reform with resistance economic approach. Shiraz. 